\title{
How to Improve Primary Health Care and the Meaning of Primary Health Care
}

\author{
$\mathrm{Na}$ Wang \\ Department of Anesthesiology \\ The First Hospital of Jilin University \\ Changchun, China \\ wangna080613@163.com
}

\author{
Jinguo Wang* (corresponding author) \\ Department of Urology \\ The First Hospital of Jilin University \\ Changchun, China \\ wangjinguolily@163.com
}

\begin{abstract}
Primary health care is still a focus in world health work today. Primary Health Care is a kind of basic health care, which depends on the feasible and reliable methods and techniques welcomed by the whole society. It works through personal and family full participation and popularization and the cost relies on self-reliance and self-conscious spirit afforded by various stages of the society. Primary health care is the center of the national health system and the main part is part of the national health system and improved with the whole social development. It is the first ring with which a personal, family and community contact with national health systems, so it makes health care as close as possible to people's life and work. According to the literature, we analyze the current status of our country and recommend strengthening training of primary health care providers.
\end{abstract}

Keywords-primary health care; training strategy; system construction

\section{INTRODUCTION}

Primary health care (PHC) providers are important elements in the work, is the health work comprehensively implement the scientific concept of development, improving people's health level and the comprehensive construction welloff society's important force. Therefore, primary health care provider's knowledge skill level is directly related to success or failure of the entire national health work. In April 2009 of our country "the central committee of the communist party of the opinions of the state council on deepening the reform of medical health system" will also improve the training of medical personnel to strategic position. Improve the level of primary health care provider skills training is the key. Because our country is now in the primary stage of socialism, while the pursuit of the harmonious development of society, there are some differences, the quality of primary health care providers is uneven, how to increase the most of the provider's knowledge skill levels to a new step is important research topic.

\section{PRIMARY HEALTH CARE}

After long time of exploration and hard work, all countries in the world to a certain extent, formed its own system of primary health care, build the primary health care providers have distinguishing feature each team. Combined with China's specific national conditions, generalized the primary health care providers should include relevant government workers all participating in the provision of primary health care, health workers: narrow sense of primary health care providers, including rural and urban basic health service providers, rural primary health care work is mainly composed of towns and townships, rural community health service centers and village health posts, health management and health technical personnel, the level of primary health care provider is mainly come from the community health service center (station), health management and health technical personnel. Therefore, the training for primary health care providers should focus on the grassroots health workers.

Training is an important part of modern human resource management, modern human resources management theory, the intelligence of labor and skills is the quality of human resources management an important part of. The definition of domestic and foreign scholars from different Angle of view for training proposed his own view. R. Barclay think it is through the efforts of planned, systematic training, learning or developing knowledge, skills and attitude, to achieve one or a department. Performance of column activity, its purpose is to make accept trainers to complete its work ability of appropriate training is involved in a certain amount of internal structure, driven by the program, in special trained architect and the form of some kind of relationship between individual or group, it includes: evaluation, value and motivation, goal setting can measure, important action plan, and help trainees with effective means and technology development skills, and clean up the workplace and personal life are valuable and sustainable improvement of barrier just. Domestic two scholars think that training is a learning the members of the organization to promote the formal steps, the purpose is to improve staff performance, improve its performance, and better achieve organizational goals [1].

All three of these definitions from different angles correctly describes the training, what they have in common and core elements are: training is planned formal step; training to improve or develop personal knowledge, skills, attitudes, and behavior; training in order to improve the performance of the individual or organization for the purpose.

Because human life is by far the world's most complicated subjects, the modern life science, biotechnology, and the rapid development of medical science, improve the special skills of all kinds of primary care providers, has become a worldwide 
subject, both in developed countries and developing countries are actively explore, hoping to get an effective strategic plan, so most need medical personnel in the practitioner of lifelong learning. The training of primary health care provides employee training, influenced by the development of modern training theory and practice [2].

The training for primary health care providers mainly refers to the education and continuing education after graduation, it covers the PHC provider from began to enter the organization to its career all course of the early, middle and late. At present world popular training methods are divided into on-the-job training and post training off. Education is given priority to with on-the-job training after graduation, just enter into the field of PHC provides workers led by veteran worker taught, help, and in their own work practical work experience. Continuing education stage, the PHC providers can be gained through on-the-job training or take off hillock training new knowledge, new skills and update ideas. Usually study way: to participate in academic conferences, academic lectures, workshops, special workshops, professional research and investigation, case study seminars, self-directed learning, etc.

\section{STRATEGIES FOR THE TRAINING OF PRIMARY HEALTH CARE PROVIDERS}

At present, the study of PHC provider training strategy all over the world, both in the urban communities and rural areas, are built around the following specific questions: Training requirements: training needs is to exist in the ideal performance standards and performance level, the gap between reality or embodied in the ideal working requirements and actual employees to master the knowledge, skills, or attitude levels. Training needs generally by investigating basic situation and training trainers will, in combination with the actual health work and evaluate the situation of training needs of the business. Training needs investigation method at present academia is widely applied to: observation method, questionnaire method, data method, interview method and performance evaluation method. Usually the application of information is: to participate in training personnel's gender, age, professional, cultural degree, job title, working time, training opportunities and a series of objective and subjective factors.

\section{TRAINING WAYS AND METHODS}

Training mode is the product of historical development, especially the training activities by use of some forms of organizations. It reflects the training activities between teachers and students in the process, as well as the relationship between students and students or in the form of cooperation. The history of Chinese and foreign education and training has been a lot of kinds of training, development to the present training mode can be divided into: the traditional way of training, work standard training methods and training methods of the modern high-tech [3].

In training strategy study, work standard way of training and the training of modern high-tech means the most respected, because they contain the current most popular on-the-job training, field teaching, work regular meeting, case discussions, clinical studies, remote teaching, not only solved the problem of the training interest, but also to a certain extent, $g$ Jilt accept trainers of the limit of time and space to PHC providers can choose according to their own needs for training content and resources.

Training method refers to anyone in the implementation of the training program is designed to help learners to acquire knowledge, skills, values, or behaviors are applied to a variety of strategies and its using steps and medium, etc. The modern training methods from the traditional single teaching method through the demonstration class, team construction methods involved in development to continuously meet the personalized method of accepting trainers now.

Draining effect evaluation: training effect evaluation is based on the previously specified training objectives and training needs, using the scientific theory, method and procedure, collect information from the training process and related data, measure of value and significance of training process.

Draw lessons from other industries advanced training strategies: this is the foreign advanced research field of advantage. In the PHC provider and the entire health personnel team training should pay attention to different industries in the process of research training achieve mastery through a comprehensive study of advanced experience.

\section{TRAINING STRATEGY AND STATUS OF FOREIGN PRIMARY HEALTH CARE PROVIDERS.}

Countries around the world generally exists the problem of insufficient health workforce, and PHC work in rural areas obviously lags behind that of urban areas. Overseas training on rural PHC provider also mainly concentrated in the training of medical staff, especially in the area of general practitioners continue to education, the representative training strategy mainly has the following kinds: In the UK, specialist and general practitioner is the main rural $\mathrm{PHC}$ provider, training process is independent, college education is similar to the United States, but in the end must be registered. General practitioners need at least nine years of medical education and job training, qualified general practitioners, registered to attend the royal GPS institute of continuing medical education (CME).

Australia has a very good experience in general medical education. The royal Australian college of general practitioners opened in the RACGP training plan in rural medical training project, project time for 4 years the focus is rural health and rural health services, the trainee time for training in general medicine for at least 12 months. At present, the health technical personnel in countries with high quality are the strict degree education, at the same time, also attaches great importance to education [4]. About CME has transition to the legalization of the stage. $\mathrm{CME}$ in the UK, although is not mandatory, volunteered for the $99 \%$ of the doctors. The government every year to offer certain reward those who participate in the CME, general practitioners to sign up to attend the royal general physicians CME activities of the organization. Continuing medical education in Australia has accumulated rich experience, has Provided to rural doctors CME project, as well as the development of a large, is the establishment of the rural medical education satellite network, the network training 
program designed by general practitioners, and for general practitioners.

\section{FOREIGN RURAL PHC PROVIDER TRAINING RESEARCH}

\section{A. The training effect evaluation research.}

Cloth card in training effect evaluation made outstanding contributions, he put forward is called "assessment clock" assessment of the steps is overseas for PHC provider training effect evaluation is more the process." Assessment of clock" process roughly: clear pattern assessment objective - to determine assessment projects and a design evaluation principles and evaluation method for evaluating the subject a evaluation index system to choose and design data mining tools a formation evaluation scheme, implementation of assessment activities compose evaluation report a feedback evaluation results, put forward opinions and Suggestions for the improvement of training activities.

\section{B. The training mode and method of research}

Overseas for PHC provider training study, enhance interest has promoting effect to the training effect, thus developed a role playing method, situational simulation and game training method. It reflects the anthrax attacks, such as public health personnel knowledge skills and comprehensive quality, developed a set of innovative training methods. This method is based on network technology and the computer screen saver, the training content design as a set of change the screen saver, through the network and training content easy to understand, simple and use the health technical personnel's idle time and chance, greatly improving the training content of attention, and makes the training easy and fast, more and more rural grassroots organizations are actively using this kind of training method.

Moesinger $\mathrm{R}$ et al. in rural America medical personnel training has carried on the thorough understanding after, detection of rural health personnel training importance is given to in a certain extent, but still there is no criterion sex guidance, through the study of the principles of some rural health institutions after the experiment concluded that: in the suburbs, near the edge of rural city community hospital set up a research organization, can provide a good environment for rural health personnel training, and easy to guidelines for the implementation of the. Australians on rural teacher training do the research assistant diagnosis. For assistant diagnosis of teacher training in Australia has a special mechanism and method, the study found that the package training effect is good, the important reason is that the training certificate admitted from society, largely increased the enthusiasm of rural health personnel training [5].

The training courses and design research. Mount urkholder on former 50 medical colleges did set the investigation of rural health personnel training course will, based on the data from the $t$ test, found that most colleges are reluctant to set up such a course, think they do, this is not the reason is that they have to include going to the rural work of graduates in the course of practice. But Hans calling for universities to pay attention to the rural health work and city hospital health work is very different and the former is more in need of special training.

American scholar Erie Laurence using originated in order to improve the quality of service is used for the flight crew and be adapted for training for health staff training courses including rural grassroots health workers. Main contents for the cultivation of team spirit in health work, such as: how to solve the tired feeling of the work environment, team building, colleagues as well as the communication between patients and decision-making ability, ability to identify adverse factors, team, working performance feedback and improve, etc. Of some rural health workers in 8 months of training and after simple statistical analysis found that accept the training of health personnel work performance has improved significantly.

\section{TRAINING PRESENT SITUATION AND THE DEMAND OF RESEARCH AMONG REGIONS}

Australian academic Charlotte Paterson select a rural community, adopt the method of questionnaire and interview to its health workers and the local people, main purpose is to get training requirements and methods to improve information. The masses of grass-roots training needs are not satisfied work objectively is very big. Paterson think training concept model needs to be changed, mainly participatory comprehensive training mode is a more appropriate solution.

British scholar Ruth Gilbert in an informative article points out that the scientific research ability of rural grassroots surgeon needs improving, should carry out in-depth training, to improve their working enthusiasm and make medical achievements benefit the society as a whole is very necessary. At present, rural grassroots health work is causing concern all over the world, rural PHC provider is the main participants of the work. Some advanced foreign countries according to their own health system and medical education system were developed for rural grassroots health personnel training strategy, and continuously positive research and training work of each link. But due to the difference between health system abroad and domestic, there is some difference in the research on rural health personnel training.

\section{CONCLUSIONS}

PHC provider is a mainstay of the rural grassroots health work, shouldering improve people's health level, the coordinated development of economy and society, the task of building a well-off society, is the first contact with the masses of the people health guard of the medical and health services. Primary care if can't satisfy the needs of people go to a doctor, can make a lot of common disease, frequently-occurring disease patient to large medical institutions, patients caused by unreasonable flow, adding to the direct and indirect medical costs, the patient has prompted "poor disease, Chinese due to illness" vicious circle, at the same time, also can cause atrophy of the grassroots health institutions, bring to the development of grass-roots health resistance. As a result, the provider's knowledge skill level is the key to effective training is around the corner, is the focus of the medical and health system reform. In actively absorb advanced foreign experience in training at the same time, must be based on China's national conditions, to 
strengthen the research of training practice and policy, improve the level of rural PHC provider of professional skills and comprehensive quality, to improve the level of rural people's health.

\section{REFERENCES}

[1] Xu Zhaoyan, Lin Fangyu. Analysis and Countermeasures on the development of the domestic community health service. Modern Clinical Nursing. 2010
[2] Yu Xiuping. Study of the present situation and the method to push about the work of the community health service. 2005

[3] Yang Qingwei.The Investment blue book: China Investment Development Report. 2013

[4] China Medical Board of New York. The global minimum essential requirements in medical education. Medical Education (China). 2009

[5] Daniel Kessler, Mark McClellan. Malpractice law and health care reform: optimal liability policy in an era of managed care[J]. Journal of Public Economics. 2002 (2). 